Najda Ivanova

Filozofska fakulteta, Ljubljana

\title{
Jezikoslovni in jezikovni vidiki Linhartovega Poskusa zgodovine Kranjske
}

V splošnokulturnem pogledu Poskus zgodovine Kranjske Antona Tomaža Linharta (1788-1791) uveljavlja vseslovensko nacionalno idejo, zaradi česar je to delo prelomnega pomena tudi za slovensko zgodovinopisje. Izvirni tretji razdelek druge knjige, ki je posvečen ljudski kulturi Slovencev, zaznamuje začetek slovenske etnologije. V tem kontekstu članek obravnava slovensko jezikovno gradivo $\mathrm{v}$ knjigi, kot odraz Linhartovih inovativnih jezikoslovnih idej o slovenskem jeziku kot substanci, strukturi in jezikovni ideologiji, ki so v precejšnji meri oblikovale tendence v razvoju slovenskega knjižnega jezika v prvi polovici 19. stoletja.

In a general cultural sense Thomas Linhart's Towards a History of Carniola (1788-1791) promotes the all-Slovene national idea for which the work is of pivotal importance to Slovene historical writing. The novel third section of the second book, devoted to Slovene folk culture, marks the beginning of Slovene ethnography. In this context the article treats Slovene language material in the book as an expression of Linhart's innovative linguistic ideas on Slovene in terms of sub stance, structure and language ideology, which in a significant way shaped the tendencies in the development of the Slovene standard language in the first half of the nineteenth century.

Poskus zgodovine Kranjske in dežel južnih Slovanov Avstrije Antona Tomaža Linharta, ${ }^{1}$ I. knjiga je izšla 1788 in II. 1791, je temeljno delo slovenskega narodnega preporoda. Razsvetljenska ideologija avtorja, definirana kot »svojevrsten amalgam racionalizma in porajajočega se kulturnega nacionalizma« (Grdina 2001: 78), izraža duhovna iskanja izobražencev $\mathrm{v}$ prerodnem krožku Ž. Zoisa, vpliva na opus V. Vodnika, J. Kopitarja in F. Prešerna ter tako v precejšnji meri oblikuje tendence v slovenskem romantizmu na začetku 19. stoletja. V splošnokulturnem pogledu se inovativnost tega spisa kaže $\mathrm{v}$ prizadevanju, da se preseže regionalizem in uveljavi vseslovenska nacionalna ideja (Zwitter 1981: 323, Gspan 1936: 28). Tudi kot zgodovinsko delo ima Poskus zgodovine Kranjske prelomni pomen za slovensko zgodovinopisje ter oblikovanje zamisli o postavitvi slovenskega kmeta in njegovega življenja $\mathrm{v}$ središče zgodovinskega prikaza (Grafenauer 1981: 381). Izvirni tretji razdelek druge knjige, ki je posvečen ljudski kulturi Slovencev v obdobju od njihove naselitve na današnjih območjih do frankovske nadoblasti, velja za prvi poskus sistematičnega opisa ljudskega življenja in je dragocen vir za proučevanje ljudske kulture 18. st., s čimer zaznamuje začetek slovenske etnologije (Novak 1973: 60-61). Ko se je odločil za primerjalno zgodovinsko metodo, ki je $\mathrm{v}$ takratni evropski humanistiki šele nastajala, je Linhart na eni strani sicer vzdignil svoje raziskovanje na moderno znanstveno raven, na drugi pa se ni mogel izogniti nepopolnostim tega pristopa $\mathrm{v}$ začetni fazi

\footnotetext{
${ }^{1} \mathrm{~V}$ tem prispevku bomo rabili izdajo A. Linhart, Poskus zgodovine Kranjske in ostalih dežel južnih Slovanov Avstrije 1 in 2. Ljubljana, Slovenska matica, 1981, prevajalci M. Šašel Kos, A. Gspan, N. Gspan-Prešelj, urednik B. Grafenauer. Gre za najbolj strokovno in točno verzijo Linhar tovega dela v slovenščini.
} 
njegovega oblikovanja. Tako se $\mathrm{v}$ strogo zgodovinskem smislu pomanjkljivosti dela dajo razložiti $\mathrm{z}$ ne dovolj razvito kritiko virov, nepoznavanjem metod sociološkega primerjalnega zgodovinopisja, s pomanjkanjem terenskih arheoloških raziskav staroslovanskih grobov, ki so jih začeli opravljati skoraj stoletje pozneje, vse to pa je nadomeščeno z uporabo "filološke metode«, za katero Linhart najde pobudo predvsem pri Karlu Gottlobu Antonu (Grafenauer 1981: 380). Kot osnovna pomanjkljivost pri rabi jezikovnih podatkov za zgodovinsko rekonstrukcijo se poudarja nezavedanje semantičnih sprememb besed, tudi dejstva, da en sam izraz lahko pokriva nov in stari pomen. Tako se na podlagi skupnih slovanskih izrazov, podatkov iz sodobnega slovenskega življenja in Valvasorjevih obvestil ustvarja podoba o času od konca 6. do konca 8. st., ki zagotovo ni zgodovinsko verodostojna (Grafenauer 1981: 381). Ugotovljene so bile nenatančnosti, ki se jim glede na tedanje stanje znanosti ne da izogniti - na primer v IX. členu, posvečenem religiji starih Slovanov, Linhart jemlje za izhodišče poročila iz 12. st. o verovanjih polabskih Slovanov, vendar v obdobju velikega preseljevanja narodov ne moremo več govoriti o enotnem religioznem sistemu (Grafenauer 1981: 397); plug, ki ga Linhart uvršča med najstarejša orodja Slovanov na Kranjskem, se je uveljavil okrog leta 1000; ajda je $v$ virih prvič omenjena šele 1. 1426, zato njeno širjenje na Slovenskem ne more biti povezano s križarskimi vojna$\mathrm{mi}$; kozolec prav tako ne sodi v skupno slovansko obliko gospodarjenja; primerjava krestjanin - krščenica ne drži, ker je ruska beseda nastajala od 13. st. naprej v dobi mongolsko-tatarskega gospodovanja nad južno Rusijo itn. (Grafenauer 1981: 398).

Linhartovi raziskovalci najbolj ostro nastopajo proti njegovim »ljudskim etimologijam«, ne glede na to, ali so izvirne ali prevzete od Antona (na primer razlage besed župan, hlače, Bog, košulja, gosli, Slovan, Ljubljana, mesto in grad, svinec itn. so ocenjene kot včasih drzno, preprosto, in zato neuspešno sklepanje, napačno prikazovanje pojmov glede na njihov zgodovinski značaj in razvoj, kot spodrsljaj, kot /metodološko/ zgrešene, napačne, neutemeljene, nemogoče etimologije, neuporabne kot zgodovinski vir in dokaz, neposrečene povezave, neutemeljene kombinacije itn.).

Selekcija Linhartovih etimologij je s stališča sodobne znanosti nedvomno zelo pomembna in nujna. Toda samo ugotavljanje »pravilnih « in »nepravilnih « etimologij ne obsega v celoti problematike tako imenovane »ljudske etimologije«, ki ima posebno mesto $\mathrm{v}$ jezikovnem sistemu. Te vrste etimologija namreč deluje kot eden od dejavnikov v diahronih spremembah narečij (Cienkowski 1972, Varbot 2003), njena vloga v razvoju slovanskih knjižnih jezikov pa še vedno ni sistematično raziskana. Poleg tega so etimološke rekonstrukcije samo del veliko bolj zapletene lingvistične vsebine tretjega razdelka druge knjige.

V nemško besedilo je vključenih več kot 180 primerjav izvirnih slovenskih besed $\mathrm{z}$ drugimi slovanskimi in neslovanskimi jeziki $\mathrm{z}$ diahronega in sinhronega vidika. Količinsko je to jezikovno gradivo - na ozadju literarne produkcije tistega časa, ki jo sestavljajo religiozni spisi, posvetna poezija, poljudnoznanstvena in učna literatura, administrativno-uradna besedila in publicistika (Toporišič 2000: 805) - skromno. Toda $\mathrm{v}$ tem primeru je pomembna nova jezikoslovna interpretacija slovenskega jezika kot substance, strukture in jezikovne ideologije. Določene so zakonitosti jezikovnih sprememb v okviru tedanje zgodovinskoprimerjalne metode in njihove projekcije na slovenski jezikovni razvoj. V navedenih primerih so prikazane značilne pravopisne in glasoslovne lastnosti slovenskega jezika. Zaradi tipa gradiva - nabor leksemov, ne pa samostojno besedilo - so orisane predvsem besedotvorne značilnosti 
in tudi vrsta posebnosti s področja pomenoslovja, vključno z mehanizmi etimologiziranja in motivacije izpeljank. Raziskana je vloga tujk na različnih razvojnih stopnjah slovenščine, ugotovljene so pozitivne lastnosti, ki jih slovenski jezik mora imeti, da bi dosegel prestižni sociolingvistični status.

Pogled na vpliv Linhartovega dela na tok slovenskega preporoda bi bil vsekakor nepopoln brez sistematičnega proučevanja jezikoslovnih vidikov $\mathrm{v}$ tretjem razdelku. Nujen pogoj za ustrezno rekonstrukcijo jezikoslovne problematike je abstrahiranje sodobnih znotrajjezikovnih meril »pravilnosti« in "nepravilnosti« ter obravnavanje besedila kot pojava iz zgodovine slovenskega knjižnega jezika s konca 18. st.

Linhart sprejema stališče, ki se je uveljavilo $\mathrm{v}$ tedanji znanosti, da zgodovinski razvoj narodov lahko rekonstruiramo na podlagi podobnosti in razlik med klasičnimi jeziki ter sodobnimi slovanskimi in neslovanskimi jeziki. Če ima določena skupina jezikov skupno poimenovanje nekega pojma, iz tega lahko sklepamo, da je ustrezen pojav prisoten $\mathrm{v}$ življenju teh narodov, in nasprotno. $\mathrm{V}$ skladu $\mathrm{s}$ tem načelom grška, latinska, nemška in slovanska leksika skupnega izvora karakterizira način življenja $\mathrm{v}$ najstarejšem obdobju razvoja Slovanov, ko so ti sestavljali eno pleme $\mathrm{z}$ Grki, Rimljani in Germani. Navzočnost določene plasti splošnoslovanskega besedišča ustreza obdobju oblikovanja Slovanov kot posebnega naroda. Leksikalne razlike v poimenovanju istega pojma $\mathrm{v}$ različnih slovanskih jezikih ustrezajo dobi po razseljevanju Slovanov po Evropi in ustvarjanju posameznih slovanskih narodov. Na primer, raba različnih tujk za stopnice $\mathrm{v}$ slovanskih jezikih dokazuje, da so bile prvotne hiše Slovanov zelo nizke (XIII) ${ }^{2}$ po jezikovnih podatkih lahko tudi sodimo, da so Slovani poznali peč, ne pa dimnika (XIII); ker nimajo svoje besede za kuharsko umetnost, to pomeni, da so bile njihove jedi grobe in slabo pripravljene, kakor priča tudi Prokopij (XIV); pomanjkanje skupnega izraza za rokodelstvo in umetno obrt ter tudi za tesarsko umetnost dokazuje, da je vsakdo omenjene dejavnosti opravljal samostojno (XX); ker za fizične lastnosti predmetov niso nastala ustrezna abstraktna poimenovanja, lahko sklepamo, da Slovani niso imeli sistematičnih predstav o fiziki teles (XXIII) itn.

Povezovanje zgodovine jezika z zgodovino narodne kulture, zamisel, da nekaj, kar ni poimenovano $\mathrm{v}$ jeziku, ne obstaja $\mathrm{v}$ resničnosti, in vse podobne sodbe $\mathrm{v}$ humboldtovskem duhu (oziroma interpretaciji v konceptu jezikovne relativnosti Sapira-Worfa v 20. st.) se v evropski filozofiji jezika uveljavljajo prav na začetku narodnega preporoda slovanskih narodov $\mathrm{v}$ habsburškem imperiju in kot ideje o ogromnem ustvarjalnem potencialu jezika spodbudno vplivajo zlasti na razvoj slavistike in slovanskih knjižnih jezikov.

V Linhartovih diahronih rekonstrukcijah se pojavlja tudi predstava o relativni kronologiji $\mathrm{v}$ jezikovnem razvoju, seveda $\mathrm{v}$ okviru tedanje znanstvene paradigme ali v skladu s kriterijem o stopnji skupnosti besedišča (na primer, najprej nastaja predstava o poletju in zimi, ker sta oba leksema enaka v vseh slovanskih jezikih, pozneje o jeseni in najpozneje o pomladi, kar potrjujejo njena različna poimenovanja (XXIII)) ali pa v skladu s stopnjo kompliciranosti samih denotatov $\mathrm{z}$ določenega področja dejavnosti (na primer, najstarejša glasbila so narejena iz roga - rozhniza,

\footnotetext{
${ }^{2} \mathrm{Z}$ rimskimi številkami označujemo člen, ki vsebuje citirani primer iz tretjega razdelka druge knjige.
} 
novejša iz živalske kože - męh in najpozneje, $\mathrm{z}$ odkritjem strun, nastanejo gofle $(\mathrm{XVI})$ ).

V knjigi so nakazane nekatere zakonitosti jezikovnih sprememb, ki najpogosteje pridejo do izraza na glasovni ravni in se $\mathrm{v}$ skladu s filološkimi predstavami časa prepletajo s črkopisno-pravopisnimi lastnostmi. Obstoj povsem glasovne korelacije med praformo ali starejšo formo in njeno ustreznico v sodobnem jeziku dokazuje skupnost njunega izvora. Avtor ugotavlja, da so spremembe v jeziku lahko posledica: a) dodajanja (v prajeziku korenski zlog And, End $\mathrm{z}$ dodanim priporniškim glasom v nemščini da wandeln, wenden (II); Luba se v nemščini spremeni v Laiba in s pridihom ch dobimo Laibach (IV)); b) krčenja (iz povitica po krčenju dobimo potica $(\mathrm{X})$ ); c) metateze (iz starejše oblike zhępa je z zamenjavo soglasnikov nastalo kranjsko pęzha (XV)). Podobni pojavi se razširijo tudi na zloge (slovansko rosh, nemško Rogen, prvotno v pomenu 'sadež na sploh'; tudi zadnja dva zloga latinskega farago sta bila prvotno ista beseda (XVIII)).

Pri analizi nemških toponimov slovanskega izvora so bile ugotovljene nekatere medjezikovne glasovne alternacije (na primer glas $b \mathrm{v}$ besedah, ki so iz slovenščine prešle $\mathrm{v}$ nemščino, se je načeloma spremenil v labiodentalni $f$ - na primer Belinez - Flinz (IX)).

Prek konkretnih primerjav po načelu analogije se razločujejo posamezne slovnične kategorije in besedotvorna obrazila (na primer, če je razmerje med Laiba in Laibach enako kot med Bęla in Velach, gre za slovanski ablativ množine, kakor v Razhah iz Razhe, Zirklah iz Zirkle, Telzhah iz Telzhe, Belkah iz Belke (IV); v sporu z Antonom glede etimologije besede Slovan je poudarjeno besedotvorno obrazilo -lo: Sedęti, fedilo, fedlo kot masat - maflo, kadit - kadilo (II)).

Pri približno četrtini primerjav je kranjščina primerjana $\mathrm{z}$ neslovanskimi jeziki. Na eni strani je odkrivanje slovansko-grško-latinsko-nemških paralel dokaz starodavnosti ustreznega slovanskega leksema in njegovega nastanka v dobi, ko so bila štiri plemena ena celota. Na drugi strani pa avtor loči novejšo plast tujk, ki so jih slovanski jeziki, in posebej kranjski, prevzeli v svojem individualnem razvoju.

Precejšen del primerjav, ki ugotavljajo pripadnost arhaičnemu leksikalnemu fondu, je prevzet prek Antona. To so predvsem leksemi s področja vojskovanja (bron, šcit, kopje (VIII)), religije (Bog (IX), duh (XXII)), poimenovanja naselij in zgradb (palanka (VIII), hiša, streha (XIII)), jedi (mleko, kruh, hleb (XIII)), domačih živali (búk - bik, vol (XVII)), poljedelskih orodij (plug - ploh (XVIII)), obrti (tkati, platno $(\mathrm{XX}))$ itn. Tako Linhart - po Antonu - glede poimenovanja Bog poudarja, da je slovansko, grško, rimsko in germansko dojemanje nastalo iz skupnega izvora (X); poimenovanji duh in duSha kažeta, da se Slovani, tako kot Grki, Rimljani in Germani, ne morejo osvoboditi materialnega in se povzpeti $\mathrm{v}$ duhovno sfero - duh in človeška duša sta za njih le dih - prim. gr. $\pi v \varepsilon \tilde{\mu} \mu \alpha$, lat. spiritus, nem. Geist (XXIII); tkanje je tudi zelo stara obrt, za katero so Slovani ustrezne nazive sprejeli skupaj z Grki, Latini in Nemci iz istega izvora - nem. Tuch in Zeug, dolnjesaško

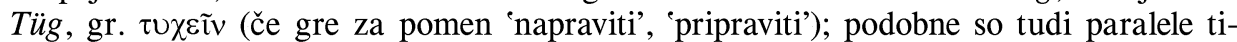
pa: shit - lat. scutum, germ. Schutz (VIII); naziv hisha, podedovan iz nomadskega življenja - lat. casa, nem. Haus, Hütte; Stręha je sorodna z nem. Stroh, Streu, lat.

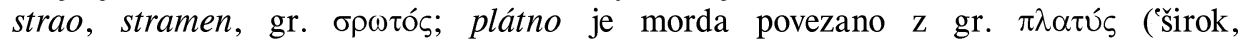
razširjen') in nem. platt ('plosk, ploščat') (XX) itn. 
Predstava o skupnosti štirih primerjanih jezikov je omogočala opravljanje semantičnih rekonstrukcij na podlagi analogije (na primer slovanska/kranjska beseda

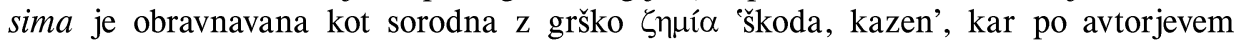
mnenju pojasnjuje negativno predstavo Slovanov o zimi (XXIII), ker v grččini ßoń pomeni 'vpitje' in 'vojska', tudi v ruščini бою pomeni 'tuliti' (VIII). Vendar pa takšni sklepi ne ustvarjajo predstave o pasivnosti in podrejenosti Slovanov pri uporabi skupnega jezika. Na primer glede besede paftir avtor poudarja, da je Slovani niso prevzeli šele od Latincev, temveč so jo izoblikovali skupno, ko so še tvorili z njimi eno ljudstvo (XVII); bukviza tudi ni izposojenka iz nemščine, ampak je nastala še pred ločitvijo posameznih plemen (XXII). Samostojnost in jezikovna ustvarjalnost Slovanov v tem obdobju kažeta na to, da je bila praslovanska dediščina, v kolikor se jo $\mathrm{v}$ kranjščini da ugotoviti, prestižna leksikalna plast, ki priča o avtentičnosti in starodavnosti slovenščine. To pa je teza, ki se $\mathrm{v}$ jezikovni ideologiji pojavlja tudi pri oblikovanju drugih slovanskih nacionalnih knjižnih jezikov.

Ideologizacijo te vrste primerjav potrjujejo primeri, v katerih se prav prek dokazovanja arhaičnosti določenega leksema spodbijajo negativne ocene tradicionalnega zgodovinopisja o slovanstvu. V členu, posvečenem narodnemu značaju, je glagol kradem v pomenu 's silo vzamem' obravnavan brez negativnih konotacij, kakor ga rabijo tedanji bosanski in vlaški roparji (v nasprotju s 'skrivno krajo' - татьба, pri kateri je nizkotnost takega ravnanja utemeljena le s skrivanjem - таю). Linhart z določenimi zadržki (»če se ne motim«) dodaja, da je morda ta beseda sorodna $\mathrm{z}$ grško $\chi \rho \alpha \delta \delta \dot{\omega} \omega$ in latinskima quatio, infestor (VI). Podtekst takšne vrste primerjav je morda naslednji: če imajo Grki isti pojem in poznajo isti pojav, nimajo pa jih za kradljivo pleme, bi moralo enako veljati tudi za Slovane. Pri obravnavanju petih pomenov besede gofpod je kot izvirni določen goft, »kar se mi zdi dokaz, kako sveto je bilo pri tem ljudstvu gostoljubje«. Prav v tem kontekstu, skupaj z običajnimi primerjavami z drugimi slovanskimi in sosednjimi jeziki, so dodane ustreznice Hofpes, Hostis, nem. Gast (VII).

Druga vrsta tujk, ki jih Linhart obravnava, so praviloma poznejše izposojenke iz sosednjih jezikov, ki odsevajo spremembe $\mathrm{v}$ običajih in načinu življenja (na primer najstarejše poimenovanje za ples je plę, ki so ga ohranili tudi Kranjci; potem ko so se Slovani razselili, so izmislili druge plese ali pa se naučili tujih - prim. pri Rusih 'golobji ples' голубеч, pri ilirskih Slovanih kolo < gr. ұорвía in tuji Tanez (XVI)). Linhart prikazuje vrsto slovenskih realij - na primer posebej poudarja posode za pitje, ki so doživele največ sprememb in ki jih zdaj Kranjci imenujejo po nemško; takratno besedo za krilo pri Kranjcih meslanka izpeljuje iz italijanskega mezza lana (XV); Slovani na Kranjskem, ki trgujejo s sosednjo Italijo, poimenujejo novce "povsem po italijansko" - sold, vinar, libra (XXI) itn. Pri obravnavi te leksikalne plasti je implicitno prisotna ideja o manjši prestižnosti poznih izposojenk, ki je posebno odločno poudarjena pri analizi tujk v toponimiji.

Avtorjev najpomembnejši cilj je dokazati, da so številni nemški toponimi na slovenskem jezikovnem območju zamenjali slovanska poimenovanja iz starejših časov. Kot nemške toponime, ki potrjujejo slovanski značaj naselij, navaja tiste $\mathrm{z}$ elementom Windisch(e), na podlagi dejstva, da je to naziv, ki so ga Nemci dali Slovanom na Kranjskem, Štajerskem in Koroškem - Windische Mark, Windischgraz, Windischfeistriz, Windische Büheln, Windischgarsten $\mathrm{v}$ Avstriji in celo $\mathrm{v}$ imenu Windischmatrei na Tirolskem (II). Ugotavlja skupno poreklo frekventne toponimične komponente 
-burg s slovansko ustreznico - grad (IV); v istem kontekstu obravnava: imena območij in naselij, ki so bila last Celjskih grofov in ki vsebujejo besedo knez - zdaj zamenjano z Graf(en)-, npr. Grafenweg - Knęshi pot, Grafenwiese - Knęshnek, Grafenbrunn - Kneshák, Kneshija (VII); poimenovanja, ki označujejo ljubezen in privrženost ljudstva svojemu bivališču in so razširjena povsod po slovanskih deželah, s posebno velikim številom primerov iz slovenščine (Lubno, Lubel, Luben, Lublana itn. (IV)); zemljepisna imena s komponentama bog in bel (pri čemer poudarja tendenco, da Slovani/Kranjci delajo toponime iz nazivov barv): Bohin, Bogatin, bohinfka Bęla, korofhka Bęla, Bęlfhiza, Bled, Bęlz, Belak itn. (IX). Našteti primeri ponazarjajo veliko besediščno in besedotvorno bogastvo slovenščine, ki je bilo zatrto pod poznejšim vplivom nemščine. Ni naključje, da je v lingvistični analizi prav te vrste leksike Linhart najbolj angažiran in samostojen. V primerih tipa Laibach poskuša ugotoviti ustaljene nemško-slovenske glasovne alternacije, ki omogočajo rekonstrukcijo prvotne slovanske besede na podlagi nemškega leksema s pomočjo odstranjevanja diftongov in aspiracije (Laibach - Luba, ne pa "neverjetna izpeljava"Lauer Bach). Ob tem meni, da je tendenca, da se vse razlaga s pomočjo nemščine, trenutna moda (IV) oziroma indirektno ocenjuje ta pristop kot nekaj začasnega in površnega. Linhartova motivacija postane še bolj jasna pri razlagi oblike Felkamark iz Belka, kjer poudarja, da se čuti dolžnega »vrniti to ime slovenskemu jeziku«(IV). Pri analizi že omenjene slovensko-nemške glasovne alternacije $b-f$ zatrjuje, da jo lahko dokaže $\mathrm{s}$ pomočjo stotih primerov, in dodaja, da bo navedel samo kranjska krajevna imena. Očitno je, da se Linhart zaveda pomembne vloge slovenske toponimije kot vira za dokazovanje enotnosti slovenskega jezikovnega območja in na drugi strani kot sredstva za ustvarjanje nestrpnosti do nemških tujk, s čimer pripravlja tla za uveljavitev purizma $\mathrm{v}$ knjižnem jeziku $\mathrm{v}$ prvih desetletjih naslednjega stoletja.

$\mathrm{V}$ knjigi seveda prevladujejo primerjave med slovanskimi jeziki, pri katerih se avtor spet opira na Antona. Toda Linhart ne posnema virov, polemizira z avtorji določenih etimologij, ponuja svoje rešitve (prim. poimenovanja Slovan (I), Ljubljana (IV), spor s Popovičem, Dobnerjem in Antonom glede besede župan (VII), preciziranje pomena besede starašina (XI) itn. (za podrobno primerjavo med Antonovima in Linhartovima interpretacijama glej Novak 1973). Sam način strukturiranja empiričnega gradiva napoveduje originalno avtorjevo zamisel. Cilj naštevanja besed, ki so formalno in semantično podobne $\mathrm{v}$ različnih slovanskih jezikih, ni rekonstrukcija ustreznih praform, temveč dokazovanje sorodnosti sodobnih slovanskih jezikov ter umeščanje in določitev vloge kranjščine $\mathrm{v}$ tem kontekstu. $\mathrm{V}$ razdelku so navedeni primeri iz hrvaščine, dalmatinščine, slavonščine, češčine, poljščine, gornje- in dolnje lužiščine, ruščine, redkeje iz slovaščine, ukrajinščine, kašubščine in polabščine. Število primerjanih jezikov variira, toda praviloma je na prvem mestu kranjščina, ki prevzema različne funkcije in vstopa $\mathrm{v}$ različna razmerja $\mathrm{z}$ ostalimi jeziki.

Izstopajo predvsem primeri, ko oblike z značilnimi kranjskimi glasovnimi in pravopisnimi lastnostmi zamenjajo splošnoslovanske lekseme - praforme - prim. trditve, da so stari Slovani nosili zhępez (XV), da se je nekoč žito imenovalo rosh (XVIII), da

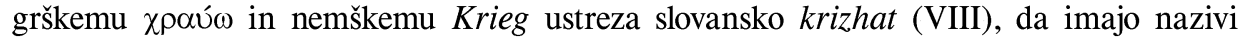
za svečenika žrtvovalca in žrtveni oltar v ruščini in drugih jezikih korensko besedo shręti (X); »slovanski ablativ« pa ponazarjajo kranjski toponimi (IV) itn.

V drugi vrsti primerjav kranjščina pridobi na vrednosti $\mathrm{z}$ argumentom, da je to edini jezik, ki je ohranil najstarejši pomen določene besede. Na primer ideja o obsto- 
ju slikovne pisave pri starih Slovanih, ki je prevzeta od Antona, je pojasnjena s prisotnostjo glagola pisati $\mathrm{v}$ vseh slovanskih jezikih, medtem ko je pojem slikanja ohranjen le v kranjskem narečju - pifano (XII); izvirna imena mesecev so se večinoma izgubila, toda Kranjci so še vedno ohranili nekatera od njih - pri njihovem naštevanju in razlagi so samo štirje od dvanajstih primerjani z drugimi slovanskimi jeziki (XXIII).

Ko je $\mathrm{v}$ nizu ustreznih oblik ohranjena njihova formalna, ne pa tudi semantična identiteta, Linhart govori o možnosti semantične diferenciacije $\mathrm{v}$ individualnem razvoju jezikov (prim. oblikovanje dveh pomenov leksema slovo - 'beseda' in 'črka', tudi besede shtęti - 'štejem' in 'berem' v različnih jezikih, ki odsevajo različne vidike hieroglifne pisave iz obdobja pred razseljevanjem Slovanov (XXI); na podoben način so opisani pomeni besed kolęda, kolędovati: pri Uskokih 'zažiganje velikih kresov', pri Čehih in Poljakih 'božično darilo', pri Kranjcih 'peti božično pesem' in pri Rusih 'čarati’ $(\mathrm{X})$ ).

$\mathrm{V}$ tej vrsti primerjav kranjsko besedišče nastopa kot nosilec sekundarnega poimenovanja glede na izhodiščno semantično varianto, ki jo izraža ustrezna splošnoslovanska beseda - na primer leksem hram v ruščini in češčini označuje 'tempelj', v kranjščini pa tako imenujejo samo neke stare zapuščene cerkve $\mathrm{v}$ skromnem srednjeveškem stavbinskem slogu $(\mathrm{X})$; isba prvotno pomeni 'votli predel med štirimi stenami in streho', zdaj je to pri Kranjcih 'prostor pod streho hiše' (XIII); lava je 'klop', v Bohinjski dolini pa je lęva 'ognjišče zraven peči, na katerem hranijo treske za luč ' (XIII); palanka v Bosni in Srbiji pomeni 'trdnjavo, prostor za obrambo', v kranjščini pa planka označuje 'ograjo iz desk' (VIII).

Konfiguracija oblik, primerjanih na ta način, se lahko spremeni - na primer tkanje pri starih Slovanih označujeta splošnoslovanski besedi platno in sukno. Linhart dodaja tudi kranjsko pèrt in pravi, da je to srednja vrsta, ki je ne zna razložiti, toda pri Kranjcih pomeni 'platneno sukno'. Navaja ustreznico le iz ruščine портище s pomenom 'toliko sukna, kolikor ga je treba za obleko' (XX). Torej, kranjska oblika funkcionira kot arhaična 'praforma', njen splošnoslovanski pomen pa dokazuje istokorenska ruska beseda, ki je nosilec sekundarne pomenske sestavine.

Nekatere Linhartove primerjave imajo panslavistično motivacijo, katere namen je dokazati jezikovno enotnost med severnimi Slovani, zlasti Rusi in Kranjci, kot dvema skrajnima deloma Slavie. To na primer potrjuje dejstvo, da imata dve skrajno oddaljeni plemeni stara naziva комната in zhumnata za zaklenjeno kamro (XIII); na podlagi Adelungovih in Möhsenovih sklepov o novcih, imenovanih Finkenaugen in Okelpfenninge (z notranjo formo 'repa' ali 'oko') pri Slovanih v severni Evropi, Linhart izpelje primerjavo s kranjskimi reparji $(<$ repa) ter hkrati poudarja njihovo analogno vlogo za južni del slovanstva (XXI). Ideologizacija je izražena tudi pri razlagi ruske besede крестянин (iz крест) in kranjske kerfheniza ('krščena dekla'). To podobnost avtor povezuje $\mathrm{z}$ obdobjem pred podjarmljenjem Slovanov, ko so ujete kristjane kot maščevanje sovražnikom izkoriščali za obdelovanje polj in hišna opravila (XVIII). Razlaga namiguje na prestižni družbeni status Slovanov pred časom, ko se je Sclavo izgovarjalo »brez glotnika« Slavo.

$\mathrm{V}$ primerih, ko v kranjščini ni ustreznice za stari splošnoslovanski leksem, Linhart spekulativno navaja drugo splošno razširjeno izpeljanko iz istega korena. Ta- 
ko v kranjščini ni trebnika ('oltar') kot v ruščini, toda obstaja trębuh (kake živali), trębiti ('čistiti'), tręba ('nujnost', 'usoda') in tudi Trebnje, Trebno (X). Kranjščina ne pozna naziva za tesarja, ki bi ustrezal ruskemu плотникъ, toda ostali jeziki, tudi kranjščina, imajo lekseme tipa plot, pledem (XIII).

Ko je slovensko besedo izrinila tujka, je to posebej poudarjeno - torej, slovenščina je poznala staro besedo $\mathrm{v}$ prejšnjih fazah svojega razvoja (na primer namesto vojska Kranjci rabijo italijansko besedo armada (VIII), namesto stol so skupaj s tujim običajem sprejeli tujko (XIII)).

V Linhartoven slovenskem gradivu so prikazane tipične lastnosti pravopisne in glasoslovne norme osrednjega kranjskega knjižnojezikovnega tipa tega obdobja s prevladujočimi gorenjskimi posebnostmi.

Kranjski primeri so napisani $\mathrm{v}$ bohoričici $\mathrm{z}$ značilnimi črkami in dvočrkji za razlikovanje sičnikov in šumevcev (Toporišič 1989): [s] - $\int$ ali Is (Sęlit (I), maslo (II), Jukno (XX), Vass (I), plęs (XVI)); [z] - s (svęr (XVII), jesero (XXII), slode (IX)); [c] - z (maliza (XIV), lovez (XVII), ovza (XVII)); [č] - zh (mezh (VIII), hlazhe (XV), hudizh (IX)); [ž] - sh (koshuh (XV), shivina (XVII), noshniza (VIII));

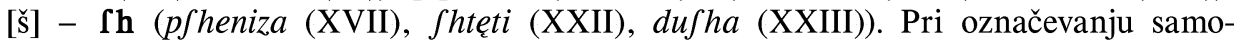
glasnikov so rabljena naglasna znamenja, ki določajo mesto ali/in kvaliteto vokala: a (hala (XV), beshat (IX), zhara (IX)) - à (boshàk (IX), piskàr (IV)) - á (otáva, jáfle (XVII), volnák (XVII), plátno (XIX)); e (Slovenz (I), shena (XI), vezherja (XIV), fled (IX)) - è (lonèz (XIV), ofèk (XVII), ovè (XVIII), dèsh (XXIII)); za ozki $e$ - ę (knęsa (VII), męfto (IV), pę̧zi (VIII), objęd (XIV), vezhęr (XIV), fvęt $(\mathrm{IX}))$; o (potiza $(\mathrm{X})$, slode (IX)) - ó (Kórka (II)) - ò (kolò (X)), fenò (XVII), ròsh (XVIII), profò (XVIII), frebrò (XIX)); u (kupit (XX), dufha (XXII), fufhez (XXII), bukviza (XXII)) - ù ( ùkno (XX)); zlogotvorni $r$ - êr, èr, ér, er (kêrft, Kérftnik (X), Popèrtnik, pèrt (X), Tèrst (IV), zhèrni bog (IX), ferna (XVII), dèrvo (XVIII), Jèrp (XVIII), erdęzhe (XIX)).

Kažejo se tudi naslednje tipične glasoslovne lastnosti (prim. Smole 2001): ě > ozki e (Bęla, Belkah (IV), mefto (IV), pobęgnit, bezhat (IX), fvetloba, fvęt (IX), nevęta (XI), svęr (XVII), leto (XXIII), Jtręha (XIII), shelęso (IX)) in zelo redko dvoglasniški refleks pod vplivom dolenjske knjižne tradicije (mejfez (XXIII)). Analogni refleks ima nosnik sprednjega reda (knęsa, Kneshak (VII), kolędovat (X), fvęt (IX)); ą > o (gof, gofle (XVI), pot (VII), roka (VIII), mofhki (VI)); refleksi polglasnika (lovez (XVII), sajez (XVII), oves (XVIII), traven (XXIII), vęter (XXIII), lonez (XIV)); zlogotvorni $1>$ ol (volk (XVII)); labializacija a-ja (shol, kimovz < kimavez po redukciji (IX)); dosledno se pojavlja vokalna redukcija (shalovat (I), flovenz (I), pobegnit (IX), Radolza (IX), babza (XI), vilze (XIV), kofit (XIV), prosenz (XXIII), ogn (XXIII), varvat (IV)); redukcija in vokalizacija $\mathbf{r} \mathbf{v}$ predponi pri- (persega, perjatel, perjeti (VII)). Sporadično so predstavljeni tudi izginotje $\mathbf{v}$ v začetnem položaju in protetični $\mathbf{v}\left(o \int e k-v o l n a ́ k<u l\right.$ (XVII)), in-

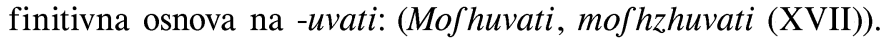

$\mathrm{Na}$ področju konzonantizma so opazni različni rezultati depalatalizacije $l$ ' in $n$ ': l'> jl, 1 (Krajl (VII), poftela (XIII), Lublana (IV), perjatel (VII), semla (XXII)), n'> jn, n (Kojniki, kojniza (VIII), Jukna, Jvina (XIX), oshęnen (XI)); poenostavitev sklopa šč > š (Gradifhe (IV), fhit (VIII), kersheniza (XVIII), VojShak (VIII)) in tudi značilne soglasniške skupine (bogaftvo (IX), buzhela (XVIII)). 
Najbolj podrobno so opisane besedotvorne značilnosti kranjske leksike. V kontekstu etimoloških rekonstrukcij Linhart uvaja določene termine, ki označujejo razmerje med podstavo ali korenom in izpeljanko (na primer označevanje $\int e ̀ l, ~ \int l$ kot »debelni zlog « besed Selit, Selęnje, felo, Selifhe, fel (II); trditev, da je fedęti »korenska beseda « leksema fedlo (II) in v isti funkciji shręti za besede, ki so povezane z žrtvovanjem pri starih Slovanih (X); skupni »korenski zlog « bor, var besed Burg in grad, $\mathrm{z}$ izpeljankama boriti, varvati (IV)). Avtor loči primere besedne tvorbe $\mathrm{s}$ pomočjo prefiksacije (poroka < po-roka (VII), persega < при, pri, przi, pshe fęgat, fięgac, fsahacz (VII)) in s pomočjo sufiksacije, pri čemer poudarja že omenjeno besedotvorno obrazilo -lo (II). Obravnava možne glasovne spremembe na meji med podstavo in pripono (prim. njegovo mnenje, da oroshje izhaja iz ruda - rushno, ne pa iz roka, ruka; v nasprotnem primeru bi se izpeljanka glasila orozhje, oruzhje (VIII)). Izločeni so primeri zloženk (na primer Svantevid < svęt - vidim, zhernibog $<$ zhern - bog (IX)).

Poleg morfoloških načinov tvorbe besed navaja tudi primere za preoblikovanje besednih zvez (na primer popèrtnik < po pèrti, z značilno končnico za mestnik m. sp. edn. $-i(\mathrm{X}))$.

Od besedotvornih pomenov sta ugotovljena modifikacija in zlasti pomanjševanje (Belka < bęla (IV), Boshizh, boshàk < Bog (IX), maliza < malo (XIV)).

Kranjski jezik je predstavljen v več kot 60 domnevnih besedotvornih parih in družinah, ki naj bi potrjevali njegov bogat besedotvorni potencial.

Linhart loči naslednje derivacijske pare: lov - lovez (XVII), kolo - kolazh (X), vila - vilze (XIV), rog - roshniza (XVI), oko - okno (XIII), vezhęr - vezherja (XIV), zhręv - zhręvle (XV), ul - volnák (XVII), hlęv - pohlęvnoft (XVII), pir pirhi (XIV), plug - ploh, brana - bruno (XVIII), fedem - Jedmina; shivim - shivina (XIV), plazhati - platno (XXI), Jukati - Jukno (XX), perjeti - perjatel (VII), krushit - kruh (XIV), pifati - pifano (XXII), morati - mora (IX), sliti, izliti - shliza (XIV), kofiti - kofilo (XIV); z dvojno motivacijo: Skriti - shkrat/zhart shkrat, boj - bijem (VIII).

Besedne družine po Linhartu so: Selit - Selęnje - felo - Selifhe - fel; fledit - Sled - poflędni; Sedlo - Sedilo - Sedęti (II); nosh - noshna - noshniza (VIII); kovazh - kujem - nakovalo - podkova (XX); poftela - Jtęla - ftlati (XIII); prerok - rechi - rezhniza (IX); kup - kupit - kupzhovat - kupzhija (XXI), kolęda kolędovat - kolędniki (X); grad - graditi - ograditi - ograja (VIII); Jtan - Jtavim - ftavniza (VIII); góf - gofle - fe gody - godem (XVII); zhert - zherni bog zhern - zhara - zhartiti (IX); voj - vojfka - vojfhak (VIII); vrag - Sovrazhit Sovrashnik - Sovrafhtvo - vrasha (IX); bogaftvo - bogat - vbog (IX); mofh -

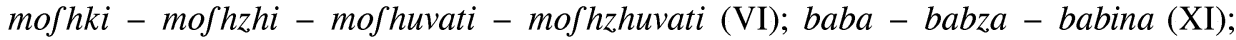
kref - krefati - kerft - kérftnik (X); sov - fovit - fov - fvat (VIII); kraj - krajl - krajel - kara (VII), trębuh - trębiti - tręba - Trebnje - Trebno (X).

V okviru semantičnega opisa kranjske leksike je predstavljenih nekaj tipov motiviranih pomenov. $\mathrm{V}$ arhaični plasti splošnoslovanskega besedišča obstaja skupina leksemov, ki so po mnenju tedanje indoevropeistike onomatopejskega izvora (ftręha (XIII), plug (XVIII), kujem (XX), supan (VII), vihar (IX), desh, blifk, grom (XXIII)) 
Linhart navaja tudi določeno število leksemov, katerih notranja forma kaže nekatere slovenske ritualne in etnološke značilnosti, vključno s paralingvističnimi modeli obnašanja (beseda perjatelftvo pomeni 'način, na katerega Kranjec pozdravlja svojega soseda, pri čemer mu ponuja roko in seže po njegovi z besedami: "Bog te fprimi!« (VI); perfega označuje 'obred slovesnega dotikanja predmeta, ki so ga imeli za svetega (VII); poroka upodablja združitev rok ali udarec v roko kot svečano znamenje zakonite zveze (VII); semantična rekonstrukcija besede Stavniza upodablja ritual postavljanja zastave na javni prostor, kjer se je zbirala vsa vojska (VIII); poimenovanje kruh kaže, da so ga lomili ali drobili, preden so ga použili /krushit/ (XIV); ritualni kruh popèrtnik so razložili po prtu (X)).

Linhart se zaveda tudi pojava polisemije. $\mathrm{V}$ tem kontekstu poudarja možnost nastajanja sekundarnih pomenov $\mathrm{v}$ zgodovinskem razvoju besede (na primer poimenovanja na področju vojskovanja v kranjščini dobijo sekundarne pomene, povezane $\mathrm{s}$ poročnim ritualom $(\mathrm{XI})$ ). Toda $\mathrm{v}$ večini primerov, ko govori o večpomenskosti, avtor dejansko združuje semantična razmerja, značilna za besedno družino, pojave večpomenskosti in paronimije (prim. trditev, da v slovanskih jezikih obstaja ena beseda za označevanje stare ženske, stare matere in ženske, ki pomaga pri porodu - za kranjščino v prvem pomenu navaja $b a b a$, za druga dva pa babza (XI); v analizi, posvečeni predstavam Slovanov o Bogu, izraža mnenje, da imajo za pojme 'heilig, Licht, Welt' isto besedo in navaja primere izpeljank iz treh korenov: svęt-, svet(l)-, svet- (IX); pri razlagi petih pomenov besede gofpod za tri navaja primere iz kranjščine: gofpod - 'nepomembni gospod v občevanju'; gofpodar - 'hišni gospodar' in paronimno obliko goft (VII)).

Raziskovalci Linharta poudarjajo, da je s sodobnega vidika en del njegovih etimologij in motivacij leksemov $\mathrm{v}$ besedotvornih gnezdih diahronično upravičen, drugi del pa je zgrajen po principu »ljudske etimologije«. Zanimivo, in hkrati razumljivo, je, da avtor njenih mehanizmov ne prepoznava na podlagi slovanskega jezikovnega gradiva, temveč $\mathrm{v}$ nemščini, ko poskuša dokazati slovanski izvor določenega leksema (na primer na podlagi podobno zveneče besede das Rad, v grbu mesta Radmansdorf/Radovljica na nekem žigu iz 1. 1571, namesto podobe moškega, ki drži kolo, domneva, da bi to mogel biti bog Radegaft (IX); pomen besede porok se da izpeljati ne iz borgen, ampak iz po-roka (VII) itn.)

$\mathrm{V}$ resnici se Linhartove kranjske etimologije ne ujemajo povsem s pojmom »judska etimologija«. Avtor najprej navaja izvirno slovensko besedo, določa njen glavni pomen $\mathrm{v}$ nemščini, potem na principu glasovne podobnosti ugotavlja druge slovenske lekseme, ki so lahko izpeljanke iz istega korena, ampak tudi paronimi. Na podlagi tega postopka lahko pride do sekundarne semantične motivacije glavnega pomena. Torej, osnovni leksem ne spremeni svoje forme, ne izgubi prvotnega pomena, ampak pri reinterpretaciji dobi novo semantično komponento in postane večpomenski, s čimer se obogati njegova notranja forma (na primer pomen besede kralj je razložen na podlagi slovenske glasovne oblike krajl; to omogoča ugotovitev paronimne povezave z leksemom $\mathrm{kraj}$ in odtod izpeljevanje pomena 'gospod nekega okra$\mathrm{ja}$, neke dežele'; glasovna podobnost $\mathrm{z}$ besedo kara omogoča dodajanje še ene komponente glavnemu pomenu: funkcije soditi in kaznovati (VII)). Na podoben način so obravnavani tudi leksemi stavnica (VIII), gosle (XVII), kres (X), črt, bog (IX), sovražiti (IX), maščevati (VI). Torej, morda je v primeru Linhartovih »etimoloških re- 
konstrukcij« bolj upravičeno govoriti o gradivu za prvi asociativni slovar slovenskega jezika kot pa dokazovati pravilnost etimologij.

Omenjeni tip sinhronih semantičnih asociacij na fonični osnovi dejansko izpostavlja glasovno specifiko jezika, aktualizira probleme njegove melodičnosti in blagoglasja, kar je ena osnovnih komponent jezikovne ideologije nastajajočih slovanskih knjižnih jezikov oziroma argument za razvoj njihove estetske funkcije. Ni naključje, da je Linhart Antonove aksiološke predstave o melodičnosti slovanskih jezikov prilagodil samo slovenščini, pri čemer poudarja, da je ravno ta jezik ustrezen za melodiko, sposoben za vsakršno oblikovanje in da skoraj dosega prijetnost italijanske poezije. V tem kontekstu Linhart omenja tudi enega od prelomnih trenutkov lastnega življenja - premik z nemščine na slovenščino, ko sta skupaj z Zoisom prevedla odlomke italijanskih opernih libretov, ki so bili sprejeti z navdušenjem. Prav idejo o blagoglasju slovenskega jezika, ki je izražena v Poskusu zgodovine Kranjske, so Kopitar, Zupan in Čop sprejeli kot argument pri zavračanju predsodkov o neliterarnosti slovenščine (Gspan 1968: 11).

$\mathrm{V}$ Linhartovem delu je torej dokazana starodavnost slovenskega jezika in njegov pomen pri vrednotenju splošnoslovanske kulturne dediščine; slovenska narodna leksika je predstavljena s kranjskim pravopisom; prek etimoloških analiz in medjezikovnih primerjav so opisane njene glasoslovne posebnosti, specifično ujemanje glasov, ki poudarja njegovo evfoničnost in sposobnost za doseganje estetskega učinka. Na drugi strani je prek remotivacije v semantiki pojmov, ki so ključni za obdobje preporoda, dokazano njegovo besedotvorno in semantično bogastvo kot potencialna osnova za prihodnjo diferenciacijo knjižnega jezika. Določeno je mesto tujk, pri čemer je izražen negativen odnos do nemškega jezikovnega vpliva, ki bo v naslednjem stoletju hitro prerasel v značilni slovenski purizem. Dokazana je enotnost slovenskega jezikovnega ozemlja, postavljeni so temelji jezikovne ideologije slovenskega preporoda in nakazana tudi vrsta konkretnih tendenc $\mathrm{v}$ oblikovanju knjižne norme.

\section{Literatura}

Cienkowski, W. 1972. Teoria etymologii ludowej. Warszawa.

Grafenauer, B. 1981. „Pripombe k drugi knjigi Linhartovega Poskusa«. V: A. Linhart. Poskus zgodovine Kranjske in ostalih dežel južnih Slovanov Avstrije 1 in 2. Ljubljana. Str. 375-400.

Grdina, I. 2001. »Slovenski apostoli avstroslavizma«. V: Slovenska kronika XIX. stoletja 1800-1860. Ljubljana. Str. 78.

Gspan, A. 1936. »Linhartova miselnost in delo«. V: Anton Tomaž Linhart. Izbrano delo. Celje. Str. 16-54.

Gspan, A. 1968. „Geneza, vsebina in stil dramatičnih del Antona Tomaža Linharta«. IV. seminar slovenskega jezika, literature in kulture. Ljubljana. Str. 1-21.

Novak, V. 1973. »Anton Tomaž Linhart o kulturi starih Slovencev«. V: Traditiones 2. Ljubljana. Str. 35-61.

Smole, V. 2001. Zgodovinska slovnica in dialektologija. Vokalizem, naglas, konzonantizem. Ljubljana. Tipkopis. 
Toporišǐ̌, J. 1989. »Bohoričica 17. in prve polovice 18. stoletja«. Obdobja 9. Obdobje baroka v slovenskem jeziku, literaturi in kulturi. Ljubljana. Str. 233-252.

Toporišič, J. 2000. Slovenska slovnica. Maribor.

Varbot, Ž. 2003. "Narodnaja ètimologija $\mathrm{v}$ istorii jazyka i v naučnoj ètimologii XIII. Meždunarodnyj s”jezd slavistov. V: Slavjanskoe jazykoznanie. Kyjiv. Str. 49-62.

Zwitter, F. 1981. "Linhartova doba, misel in delo«. V: A. Linhart. Poskus zgodovine Kranjske in ostalih dežel južnih Slovanov Avstrije 1 in 2. Str. 303-350.

Prispelo decembra 2004, sprejeto januarja 2005

Received December 2004, accepted January 2005

\section{Jezikoslovni in jezikovni vidiki Linhartovega Poskusa zgodovine Kranjske}

Članek obravnava tretji razdelek druge knjige Poskusa zgodovine Kranjske (1791), ki je posvečen ljudski kulturi in jeziku Slovencev. V Linhartovem delu je dokazana starodavnost slovenskega jezika in njegov pomen pri vrednotenju splošnoslovanske kulturne dediščine; preko etimoloških analiz in medjezikovnih primerjav so opisane glasoslovne posebnosti slovenččine, specifično ujemanje glasov, ki poudarja njeno evfoničnost in sposobnost za doseganje estetskega učinka. Po drugi strani je preko remotivacije v semantiki pojmov, ki so ključni za obdobje preporoda, dokazano besedotvorno in semantično bogastvo slovenskega jezika kot potencialna osnova za prihodnjo diferenciacijo knjižnega jezika. Določeno je mesto tujk, pri čemer je izražen negativen odnos do nemškega jezikovnega vpliva, ki bo $\mathrm{v}$ naslednjem stoletju hitro prerasel v značilni slovenski purizem. Dokazana je enotnost slovenskega jezikovnega ozemlja, postavljeni so temelji jezikovne ideologije slovenskega preporoda.

\section{Linguistic and Language-Oriented Aspects of Towards a History of Carniola}

The article treats the third section of the second book of Linhart's Towards a History of Carniola (1791), which is devoted to the folk culture and language of the Slovenes. Linhart's work shows the ancient origins of the Slovene language and its meaning for the evaluation of the general Slavic heritage. To do so he brings to bear etymological analyses illuminating specific parts of the Slovene sound system and particular sound combinations that underscore its euphony and ability to achieve aesthetic effect. On another plane, through the remotivation of key sememes for the period of revival, Linhart demonstrates the word-formational and semantic wealth of Slovene as a potential basis for the future elaboration of a standard language. $\mathrm{He}$ defines a negative position towards borrowings, which indicated German linguistic influence, a position that will in the next century quickly develop into the Slovene proclivity towards purism. Moreover, he demonstrates the unity of the Slovene linguistic territory and establishes the ideological bases for the Slovene Revival. 